\title{
Spatial Structure in Length at Age of Cod in the Barents Sea
}

Frode Vinje Lium (f.v.lium@bio.uio.no)

Mikko Heino (mikko.heino@imr.no)

Ulf Dieckmann (dieckmann @iiasa.ac.at)

Olav Rune Godø (olav.rune.godoe @imr.no)

Jarle Mork (jarle.mork@vm.ntnu.no)

\section{Approved by}

Leen Hordjik

Director, IIASA

December 2003 


\section{Contents}

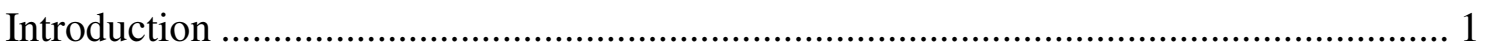

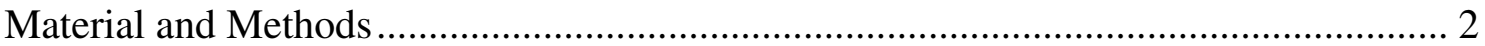

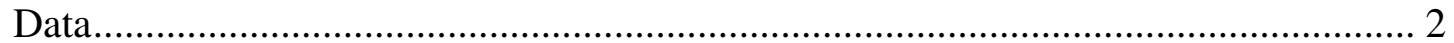

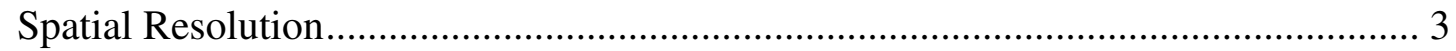

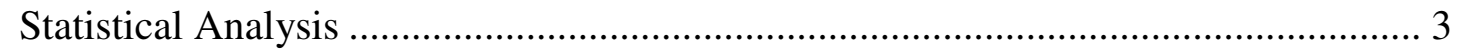

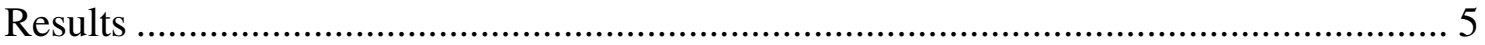

The Spatial Structure with respect to size-at-age ...................................................... 5

The dependence of length-at-age on temperature .................................................... 9

The effect of severity on predictability................................................................. 9

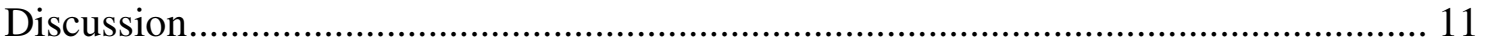

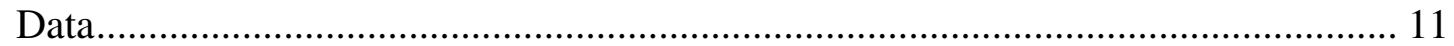

The spatial structure with respect to size-at-age ..................................................... 11

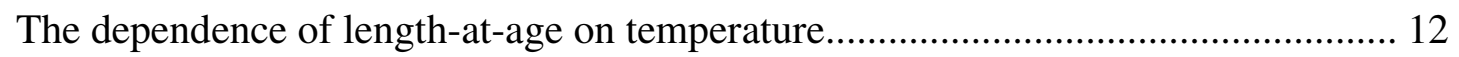

The effect of severity on predictability ................................................................ 14

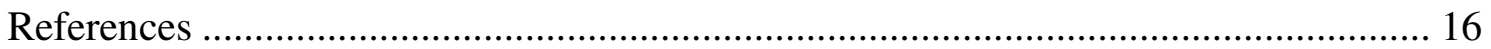

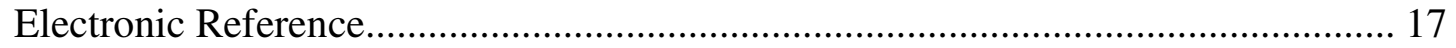




\begin{abstract}
Cod Gadus morhua population in the Barents Sea was found to be spatially structured with regard to length-at-age. Results were based on data collected during research surveys in the Barents Sea between 1982 and 1997. The identified spatial structure was most pronounced for age groups 2 to 4 years and decreased for the older age groups with higher potential for migration. A positive linear correlation between mean lengthat-age and mean geographical temperature was established for age groups 2 to 4 years. This correlation was shown to be strongest when based on mean temperatures during 3year periods ending with the year of capture. The spatial structure in length-at-age was shown to follow the temperature gradient of the Barents Sea. A large part of the observed area effects could be explained by temperature variation between areas. Evidence is also presented which indicates that the predictability and sensitivity of the dependence of length-at-age on temperature increases under extreme environmental conditions, i.e. in the northern and eastern areas of the Barents Sea.
\end{abstract}




\title{
About the Authors
}

\author{
Frode Vinje Lium \\ University of Oslo, \\ Department of Zoology, \\ P.O. Box 1050 Blindern, \\ N- 0316 Oslo, Norway \\ and \\ Adaptive Dynamics Network, \\ Schlossplatz 1, A-2361 Laxenburg, Austria
}

International Institute for Applied Systems Analysis,

\author{
Mikko Heino \\ Institute of Marine Research \\ P.O. Box 1870 Nordnes, \\ N-5187 Bergen, Norway \\ and
}

Adaptive Dynamics Network,

International Institute for Applied Systems Analysis,

Schlossplatz 1, A-2361 Laxenburg, Austria

Ulf Dieckmann

Adaptive Dynamics Network,

International Institute for Applied Systems Analysis,

Schlossplatz 1, A-2361 Laxenburg, Austria

Olav Rune God $\varnothing$

Institute of Marine Research

P.O. Box 1870 Nordnes,

N-5187 Bergen, Norway

Jarle Mork

Norwegian University of Science and Technology,

Trondhjem Biological Station,

N-7034 Trondheim, Norway 


\section{Acknowledgments}

The authors wish to thank K. Michalsen, G. Ottersen and B. Ådlandsvik for providing the temperature data used in this study, A. Ajiad for discussions and A. James for help with the figures. This research was financially supported by the Adaptive Dynamics Network (ADN) at the International Institute for Applied Systems Analysis (IIASA), Laxenburg, Austria, and by the Academy of Finland (MH; Project 45928). Collaboration on this study has been fostered by the European Research Training Network ModLife, supported by the Fifth Framework Programme of the European Community (Contract Number HPRN-CT-2000-00051). 


\title{
Spatial Structure in Length at Age of Cod in the Barents Sea
}

\author{
Frode V. Lium \\ Mikko Heino \\ Ulf Dieckmann \\ Olav R. Godø \\ Jarle Mork
}

\section{Introduction}

Cod Gadus morhua L. in the Barents Sea, known as North-east Arctic cod, is one of the commercially most important fish stocks in the world. As they are the most northern of all cod stocks, they are exposed to the extreme environmental conditions of the Barents Sea. Is this stock geographically structured with respect to size at age? If such a structure exists, could the observed life-history patterns of the fish be explained, and if so to what extent, by the temperature gradients over the stock's range?

North-east Arctic cod are a highly migratory fish stock. Mature individuals start their spawning migration in late autumn or early winter. It takes them from their feeding grounds in the Barents Sea towards the spawning grounds off the northern coast of Norway, with spawning taking place between February and April. The small size of the spawning grounds relative to the feeding grounds appears to ensure, in each generation, an efficient genetic mixing of the cod population. After spawning, eggs and larvae drift with the water currents into the Barents Sea and settle at nursery and feeding areas; these are located along the west coast of Spitsbergen and in the northern and eastern Barents Sea. These areas are strongly influenced by the polar front where relatively warm Atlantic and cold Arctic waters meet. Plankton feeders, such as capelin Mallotus villosus (Müller), benefit from the high productivity in the zone affected by the polar front (Loeng, 1991), and cod, in particular from age 2 years onwards, feed heavily on the high capelin concentrations near the polar front (Bogstad \& Mehl, 1997). Yet, the colder water masses there also result in physiologically unfavourable conditions. Cod in the south-western areas of the Barents Sea will experience more favourable temperatures but not the extreme productivity of the polar front (Bergstad et al., 1987).

Annual mean temperatures experienced by cod range from $7^{\circ} \mathrm{C}$ at the spawning grounds along the Norwegian coast to temperatures as low as $0^{\circ} \mathrm{C}$ along the polar front (Michalsen et al., 1998). Mature fish therefore experience significant differences in temperature as they migrate between the relatively warm spawning grounds and the cold feeding grounds; it has been shown that ambient winter temperatures are higher for older fish with increased migratory potential (Nakken \& Raknes, 1987; Shevelev et al., 1987; Michalsen et al., 1998; Ottersen et al., 1998). The migration of immature fish gradually increases in scope (accompanying the mature portion of the stock for part of 
its spawning migration) and is normally triggered by following the winter migrating of capelin towards the western coasts of Russia and northern Norway (Ottersen et al., 1996). Cod at ages 1 and 2 years have a more limited migratory potential and feed to a large extent on local sources of krill, amphipods, and other small-sized prey, although capelin already is the primary food source at age 2 years (Bogstad \& Mehl, 1997). Age 1 year fish appear to remain in the areas where they settled after the pelagic phase at age 0 years (Maslov, 1944, 1960; Baranenkova, 1957).

On the one hand, growth of fishes is obviously dependent on the availability of prey, which, because of the upwelling of nutrient-rich water masses at the polar front, is negatively correlated with temperature. On the other hand, the performance of the physiological (in particular digestive) processes that are necessary for utilizing sequestered food is strongly dependent on temperature (Clarke, 1993; Jobling, 1994). Despite this trade-off, several authors have suggested a positive relationship between temperature and growth, a claim based on observations of greater length-at-age at high temperatures (Nakken \& Raknes, 1987; Loeng, 1989; Jørgensen, 1992; Brander, 1995). Using data from acoustic and bottom-trawl surveys conducted in February from 1988 to 1995, Michalsen et al. (1998) showed that for age groups 2 to 6 years, the mean lengthat-age increased with annual temperature. Michalsen et al. (1998) also suggested geographic variation in mean length between cod caught west of $20^{\circ} \mathrm{E}$ and east of $35^{\circ}$ E.

The aim of the present study was to elaborate on the earlier studies in two main respects: 1) by geographic structuring of juvenile cod with respect to length-at-age in a grid of 11 squares within the Barents Sea; 2) by explaining the regional differences in length-at-age by using a new temperature atlas of the Barents Sea (G. Ottersen \& B. Ådlandsvik, unpubl. data). The atlas can be used to calculate aggregated temperature values which in turn can be used as indices of climatic conditions prevailing in different regions and in different years. The atlas-based temperature indices are different from those of Michalsen et al. (1998) in that the geographical and temporal variations in the temperature regime are characterized, rather than the ambient temperature of fish at the time of capture. This is a sensible approach given that the distribution of cod is dynamic, and their ambient temperature at the time of capture may not be representative of the ambient temperature during the whole growing season. In additionan investigation was made of whether the influence of temperature was strongest under the most severe environmental conditions.

\section{Material and Methods}

\section{Data}

The cod data used in this study originates from immature individuals caught during the annual surveys in late winter and early spring conducted during the years 1982 to 1997 in the Barents Sea $\left(69^{\circ}\right.$ to $77^{\circ} \mathrm{N} ; 15^{\circ}$ to $\left.51^{\circ} \mathrm{E}\right)$ by the Institute for Marine Research, Bergen, Norway. Captured fish were measured for total body length $(\mathrm{cm})$, sex was determined by examination of gonads, and age was determined by otolith readings. Conspicuous errors in age and length readings were removed prior to the analysis by 
checking length-at-age distributions for outliers. Such outliers were few and easily distinguished; $<0.1 \%$ of all records had to be removed in this way.

The temperature data used in this study are based on a three-dimensional 'temperature atlas' compiled by the Institute of Marine Research for the Barents Sea (G. Ottersen \& B. Adlandsvik, unpubl. data). It has been extracted from the atlas through the programme 'Tempagg' (B. Ådlandsvik, unpubl. data), which aggregates temperatures into rectangles of two degrees in longitude and one degree in latitude. All available depth intervals from surface to the bottom have been used to calculate the grand mean for such areas. Only temperatures from February to June in each year were used, corresponding to the period during which most of the growth experienced by the fish in this study took place (Jørgensen, 1992). Whereas, for some areas, the atlas contains data from partly different positions in different years, grand means for the geographical areas used in this study are based on only those positions that are consistently available throughout all years, thus avoiding any bias. In areas for which the actual distribution of cod was geographically limited (primarily in the north and east), positions incorporated into grand means were selected to conform to this information.

\section{Spatial Resolution}

For statistical analysis the total study region was divided into different areas. The chosen partitioning gave maximum resolution while retaining, within each area, sample sizes sufficiently large for statistical analysis. Based on this criterion, a $3 \times 4$ grid was defined (Fig. 1). As most of the sampling was done south of $74^{\circ} \mathrm{N}$, the latitudinal width of areas north of $73^{\circ} \mathrm{N}$ has been increased; the same applies to the longitudinal width of sub-areas east of $37^{\circ}$ E. Very few samples were recorded from the north-east corner of the study area; therefore the area D2 was extended towards the north to include these observations (Fig. 1).

\section{Statistical Analysis}

ANOVA was used to investigate the effects of age, geographical area, year and sex on the expected length-at-age of cod. In a first set of ANOVAs, all ages were analysed separately. Model selection was started with a full model including all factors and firstlevel interactions. A stepwise procedure was followed to remove interaction terms that were not significant $(P>0.05)$; factors were retained even when insignificant. This resulted in a model incorporating a Year $\times$ Area interaction term: for each age group 'Age', the length $L_{\mathrm{Age}}$ of fish was estimated as

$$
L_{\mathrm{Age}}=\alpha_{0, \mathrm{Age}}+\alpha_{\text {Area,Age }}+\alpha_{\text {Year,Age }}+\alpha_{\text {Sex,Age }}+\alpha_{\text {Year } \times \text { Area,Age }}+\varepsilon,
$$

where the constants $\alpha_{x, \mathrm{Age}}$ are regression coefficients for the factor or interaction $x$ (estimated separately for each age group and with $\alpha_{0, \mathrm{Age}}$ denoting an age-specific constant); $\varepsilon$ is the residual error component. 


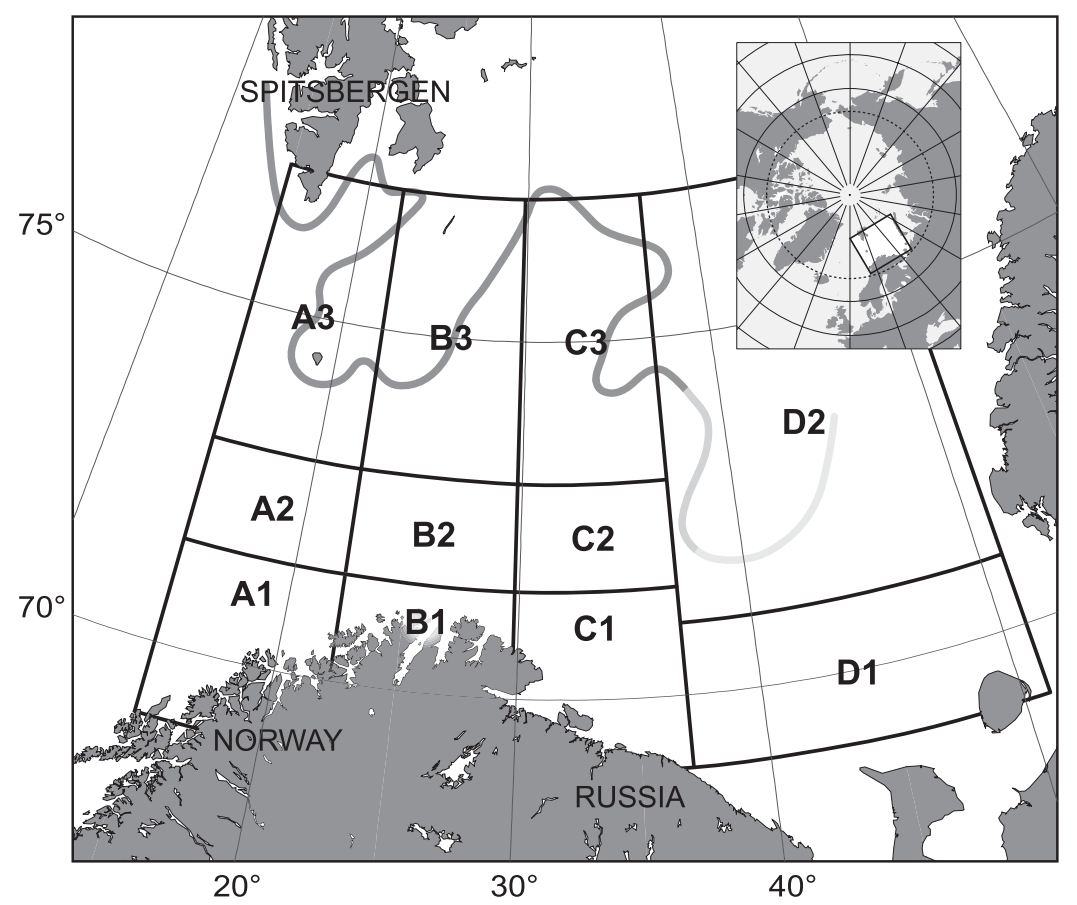

Figure 1: Map of the study region and the areas into which it is partitioned. The grey line shows the mean position of the polar front (Loeng, 1989).

In a second approach data on age groups 1-9 or 2-4 were used, age was treated as a factor, and all interactions were removed,

$$
L_{\mathrm{Age}}=\alpha_{0}+\alpha_{\mathrm{Area}}+\alpha_{\mathrm{Year}}+\alpha_{\mathrm{Sex}}+\alpha_{\mathrm{Age}}+\varepsilon .
$$

In this model the regression coefficients for year, sex and age do not depend on age; all age effects are thus accounted for by the regression coefficient $\alpha_{\text {Age }}$.

In the analyses of covariance (ANCOVA), temperature was included in model (1) as an additional explanatory variable and the Year $\times$ Area interaction was removed so as not to mask the effect of the covariate $T$,

$$
L_{\text {Age }}=\alpha_{0, \text { Age }}+\alpha_{\text {Area,Age }}+\alpha_{\text {Year,Age }}+\alpha_{\text {Sex,Age }}+\beta_{\text {Age }} T+\varepsilon .
$$

The fourth estimation was based on model (2) with temperature as a covariate,

$$
L_{\text {Age }}=\alpha_{0}+\alpha_{\text {Area }}+\alpha_{\text {Year }}+\alpha_{\text {Sex }}+\alpha_{\text {Age }}+\beta T+\varepsilon ;
$$

this model was applied to data from age groups 1-9 or 2-4 years.

A simple linear regression of length-at-age on temperature revealed the basic effect of temperature on length-at-age. For this analysis, length-at-age data were used either in the form of area-specific means for all years or as year-specific means for all areas. Temperature data were used to determine the mean temperature during the year of capture and the 2 preceding years. For an age 2 years cod this would mean including the temperature in the year of capture and from its two preceding growth seasons as a $0+$ and 1 year fish. Standardized regression coefficients (regression coefficients in which 
both the dependent and independent variable were standardized to zero mean and unity variance) and coefficients of determination $\left(R^{2}\right.$, defined as the ratio between the variance explained by the model and the total variance in the data) were used as test statistics.

The growth of cod is known to depend strongly on the biomass of capelin, its main prey species. This applies in particular to age 3 year individuals, whose growth is affected by capelin abundance for a period of 2 years. According to Bogstad \& Mehl (1997), age 3 years individuals predate mostly on age 2 and age 3 year capelin. The residuals from the area-specific regression analysis between mean length of cod at age 3 years and mean temperature were therefore linearly regressed on the average biomass of age 2 and age 3 year capelin in the years when the considered age- 3 cod individuals were 2 and 3 years old (ICES, 2001).

\section{Results}

\section{The Spatial Structure with respect to size-at-age}

Length-at-age of juvenile North-east Arctic cod exhibited strong temporal and regional variability (Table I). In the ANOVA based on Model (1), the year effect was very significant at all ages, whereas the area effect was most prominent for age groups 2 to 4 years and weaker at ages 1, 5 and 6 years. The interaction Area $\times$ Year was significant at all ages; in other words, year effects differed between areas. Sex had a statistically significant effect $(P<0.05)$ on length at ages 2,4 and 5 years, although the quantitative effect was very small at ages 2 and 4 years. All other interactions were insignificant and were removed during the process of model selection.

Temporal variation in length-at-age within areas was far greater than spatial variation within years for juvenile cod of age 2 to 4 years (Fig. 2). The response time to environmental change also appeared to be shorter in younger fish: in many areas there was a time lag between peaks of length at age 2 years and the corresponding peaks at age 4 years. Temporal variation in mean length showed a similar pattern in all areas.

To facilitate comparison between areas, all data were analysed based on Model (2). The effects of all categorical variables (area, year, sex, and age) are highly significant $(P<0.001)$. The mean lengths-at-age for all areas as predicted by this model are given in Fig. 3: they decreased from the areas in the south, west and central Barents Sea toward the areas located most north and east (areas A3, B3, C3 and D2). Model (2) was also used to analyse the data of cod at ages 2 to 4 years for comparison with the results of the analysis on all age groups. Again all effects were highly significant $(P<0.001)$. While the spatial pattern of predicted lengths-at-age for ages 2 to 4 years was the same as for all ages, differences between areas were larger in the analysis of ages 2 to 4 years (Fig. $3)$. 
Table I. ANOVA results for (a) Model (1) (age 1 to 6) and (b) Model (2) (all ages and ages 2-4)

(a)

\begin{tabular}{|c|c|c|c|c|c|}
\hline Age (years) & Source & d.f. & MS & $F$ & $P$ \\
\hline \multirow[t]{5}{*}{1} & Area & 10 & 5.241 & 1.337 & 0.204 \\
\hline & Year & 12 & 65.45 & 16.70 & $<0.001$ \\
\hline & Sex & 1 & 10.24 & 1.150 & 0.295 \\
\hline & Year×area & 101 & 12.00 & 3.060 & $<0.001$ \\
\hline & Residual & 2959 & 3.93 & & \\
\hline \multirow[t]{5}{*}{2} & Area & 9 & 65.06 & 4.350 & $<0.001$ \\
\hline & Year & 15 & 980.2 & 65.54 & $<0.001$ \\
\hline & Sex & 1 & 32.76 & 3.343 & 0.011 \\
\hline & Yearxarea & 122 & 49.84 & 3.332 & $<0.001$ \\
\hline & Residual & 6102 & 14.96 & & \\
\hline \multirow[t]{5}{*}{3} & Area & 10 & 50.36 & 2.405 & 0.008 \\
\hline & Year & 15 & 2403 & 114.8 & $<0.001$ \\
\hline & Sex & 1 & 14.56 & 1.670 & 0.276 \\
\hline & Year×area & 121 & 80.20 & 3.831 & $<0.0001$ \\
\hline & Residual & 7168 & 20.94 & & \\
\hline \multirow[t]{5}{*}{4} & Area & 10 & 105.5 & 4.461 & $<0.001$ \\
\hline & Year & 15 & 2273 & 96.17 & $<0.001$ \\
\hline & Sex & 1 & 96.24 & 6.017 & 0.009 \\
\hline & Yearxarea & 120 & 147.3 & 6.231 & $<0.001$ \\
\hline & Residual & 8037 & 23.64 & & \\
\hline \multirow[t]{5}{*}{5} & Area & 6 & 55.92 & 2.151 & 0.045 \\
\hline & Year & 15 & 1736 & 66.78 & $<0.001$ \\
\hline & Sex & 1 & 550.7 & 14.75 & $<0.001$ \\
\hline & Yearxarea & 124 & 120.6 & 4.638 & $<0.001$ \\
\hline & Residual & 6562 & 26.00 & & \\
\hline \multirow[t]{5}{*}{6} & Area & 9 & 62.89 & 2.050 & 0.031 \\
\hline & Year & 15 & 1089 & 35.53 & $<0.001$ \\
\hline & Sex & 1 & 20.83 & 2.132 & 0.156 \\
\hline & Yearxarea & 116 & 88.41 & 2.882 & $<0.001$ \\
\hline & Residual & 4410 & 30.68 & & \\
\hline \multirow[t]{5}{*}{ All ages } & Area & 10 & 3360 & 114.5 & $<0.001$ \\
\hline & Year & 15 & 25410 & 865.9 & $<0.001$ \\
\hline & Age & 8 & 932200 & 31760 & $<0.001$ \\
\hline & Sex & 1 & 2750 & 74.58 & $<0.001$ \\
\hline & Residual & 38422 & 29.35 & & \\
\hline \multirow[t]{5}{*}{$2-4$} & Area & 10 & 2392 & 96.84 & $<0.001$ \\
\hline & Year & 15 & 17350 & 702.5 & $<0.001$ \\
\hline & Age & 2 & 768700 & 31130 & $<0.001$ \\
\hline & Sex & 1 & 2216 & 62.34 & 0.007 \\
\hline & Residual & 22018 & 24.70 & & \\
\hline
\end{tabular}




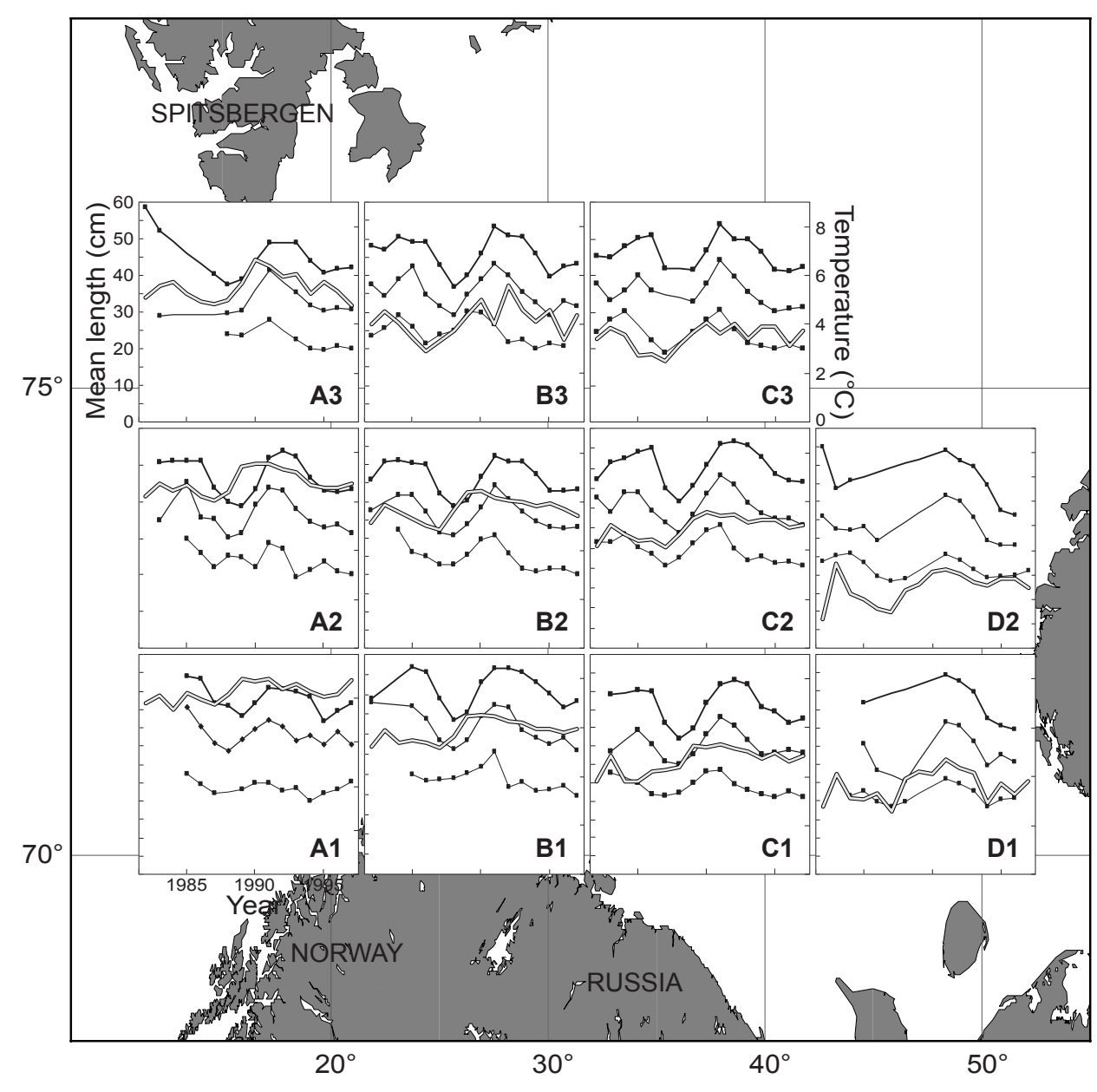

Figure 2: Mean lengths at ages $2(-), 3(-)$ and $4(-)$ years in all areas for the period 19821997. $\bullet$, all years for which length data are available. $=$ mean annual temperatures. 


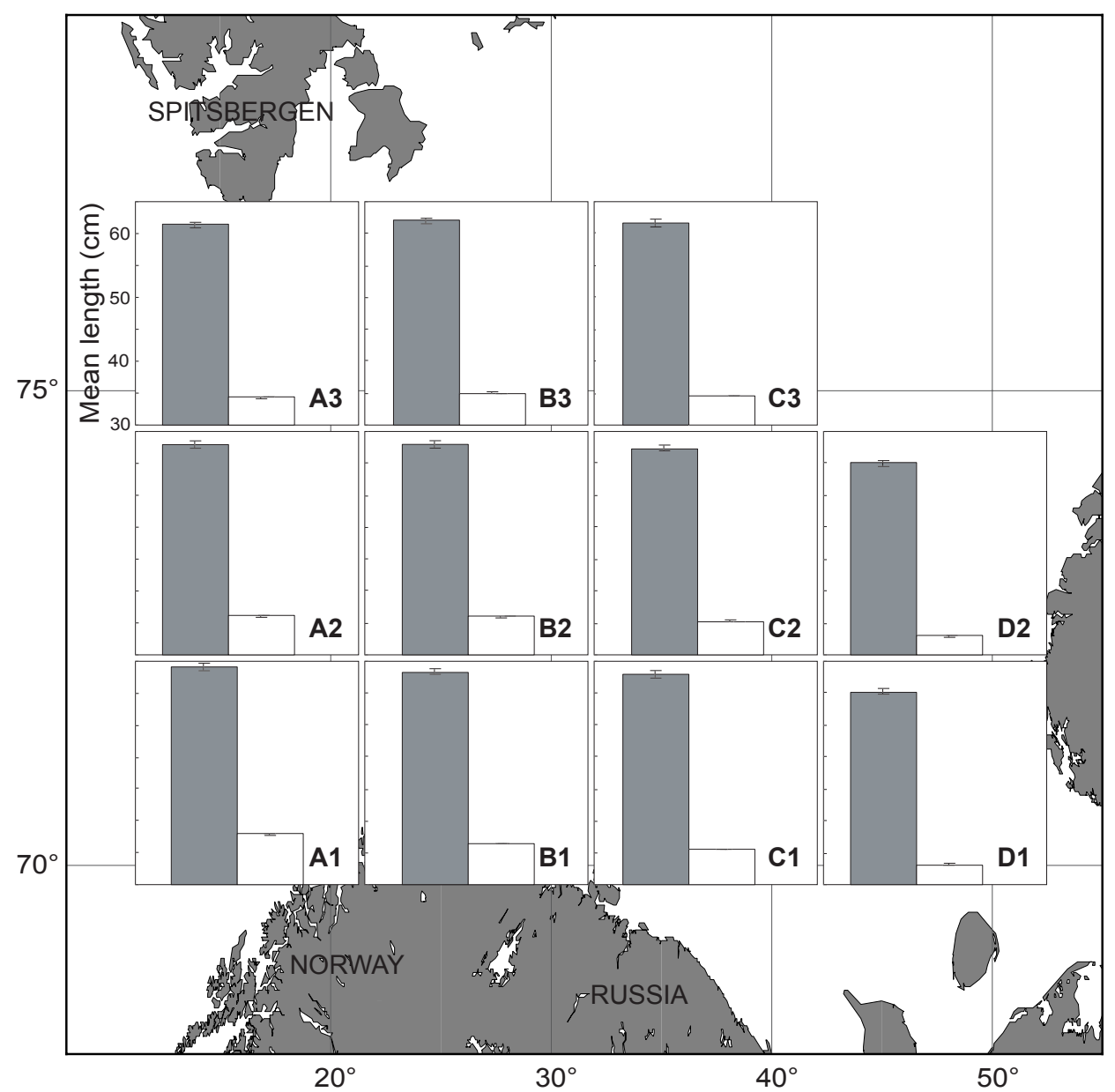

Figure 3: Mean \pm S.E. lengths predicted by Model (2). $\square$, adjusted least-square means when all age groups were included in the model, and $\square$, adjusted least-square means when only age groups 2 to 4 years were included. 


\section{The dependence of length-at-age on temperature}

The spatial structuring in length-at-age appears to follow the south-north and west-east climatic gradients of the Barents Sea. Therefore an analysis was made on whether regional differences in length-at-age could be explained by temperature differences.

The temporal fluctuations in mean annual temperature superimposed on the length at age data for the period 1982-1997 are shown in Fig. 2. The tendency of the mean annual temperature to decrease toward the northern and eastern parts of the Barents Sea is evident. It should be noted that the temperatures in the central areas (A2, B2 and C2) deviated little from those in the southern areas (A1, B1 and C1), whereas there was a

further strengthened through a series of linear regressions, based on data pooled with respect to area and sex. It is expected that the size of an individual reflects the temperatures it has experienced throughout its entire life. Therefore mean temperatures were considered, averaged over the year of capture and a varying number of preceding years. For ages 2 to 4 years, the highest degree of explanation for the regression model (measured in terms of the coefficient of determination, $R^{2}$ ) was achieved when considering mean temperatures based on the year of capture and the two preceding years. The resultant regression lines for the temperature-dependent length of cod at ages 2 to 4 years are shown in Fig. 4. The underlying statistical relationship between lengthat-age and temperature is significant $(P<0.05)$ : for example, the simple regression model explains the variability in length at age 3 years with $R^{2}=58.2 \%$.

\section{The effect of severity on predictability}

To test the hypothesis that the effect of temperature on length-at-age is strongest and most predictable in extreme environments, changes in its effect and significance from south and west towards the north and east (areas where the environment is most extreme in terms of low temperatures) were investigated.

Regression analysis was carried out between length at age 3 years and temperature for each area. The slopes of linear regressions indicate the strength of the temperature effect: the higher this coefficient, the stronger is the regression of length-at-age on temperature. The $R^{2}$ in this regression increase with the amount of variability in lengthat-age that is explained by temperature. Both the regression coefficient for temperature and the corresponding $R^{2}$ showed a clear increase toward north and east, i.e. with decreasing temperature (Fig. 5). Patterns along other transects were more complex and were probably affected by the impact of the polar front on food supply.

Following this, a test was made of whether inconsistencies in the temperature dependence between areas could be explained by data on prey biomass. Specifically, a check was made if the residuals resulting from the area-specific regressions could be explained by capelin abundance. Linear regressions between these residuals and capelin biomass available to cod at age 3 all had positive slopes (Table III). Slopes were highest for areas C3 and D2, and these areas also had the highest coefficients of determination. 


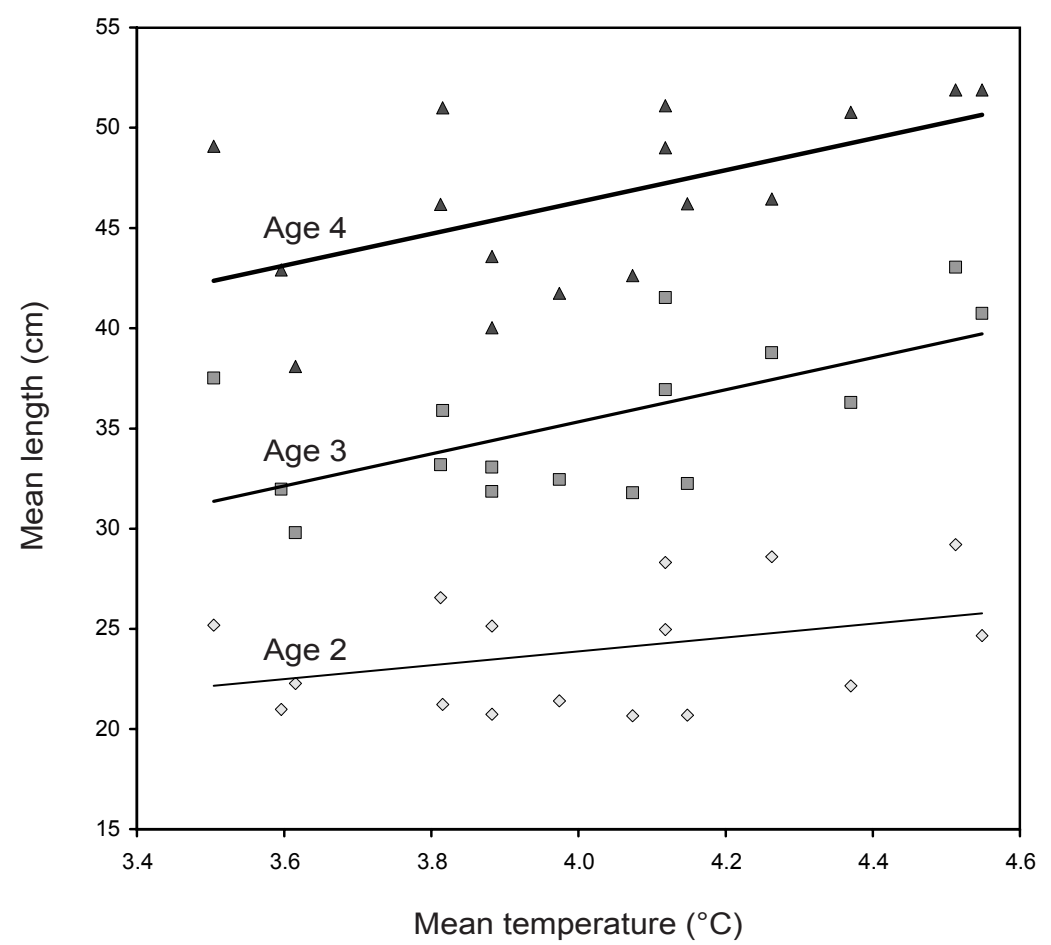

Figure 4: Linear regressions of mean length-at-age and mean temperature for age groups $2(\diamond), 3(\square)$ and $4(\boldsymbol{\Delta})$ years. Mean temperatures are based on the year of capture and the two preceding years. This choice gave the highest $R^{2}$ for the three age groups: 0.492 for age 2, 0.582 for age 3 and 0.546 for age 4 .
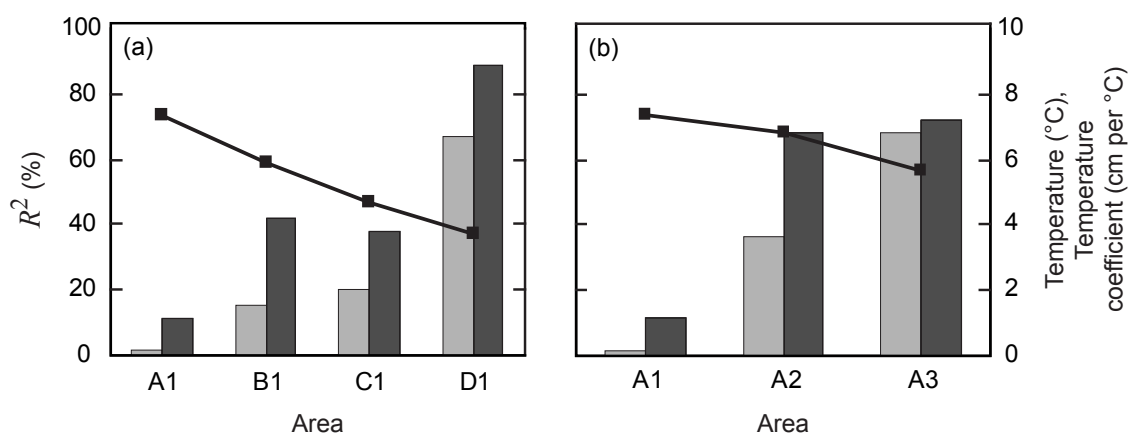

Figure 5: Mean temperatures $(\square), R^{2}(\square)$, and regression coefficients for temperature ( $\square$ ) for areas along a south-north transect (a) and a west-east transect (b), based on area-specific linear regressions of mean length at age 3 years and mean temperature. 
Table III. Linear regression coefficients of (i) the residuals from the area-specific linear regressions for the length of cod at age 3 years and mean temperature and (ii) a measure for capelin biomass available for consumption by this age group during its life up to age 3 years

\begin{tabular}{lrrc}
\hline Area & Intercept & Slope & $R^{2}$ \\
\hline A1 & 0.70 & 1.25 & 0.29 \\
A2 & 0.59 & 1.05 & 0.14 \\
A3 & 0.68 & 0.89 & 0.24 \\
B1 & 0.90 & 1.60 & 0.34 \\
B2 & 0.76 & 1.36 & 0.30 \\
B3 & 1.13 & 2.00 & 0.42 \\
C1 & 1.04 & 1.85 & 0.54 \\
C2 & 0.93 & 1.65 & 0.43 \\
C3 & 0.77 & 3.00 & 0.71 \\
D1 & 0.26 & 0.81 & 0.13 \\
D2 & 0.57 & 2.38 & 0.62 \\
\hline
\end{tabular}

\section{Discussion}

\section{Data}

The cod database used in this study was, in its entirety, collected on research surveys. Although selectivity has also been demonstrated on such surveys (Godø \& Sunnanå, 1992), its impact on measurements of age and length-at-age is considered to be minor. An exception occurs for age 1 year cod, measurements of which are affected by a change in mesh size during the time series. This selectivity bias could be one reason for the unstructured behaviour of this age group in the analysis (Michalsen et al., 1998).

The programme used to retrieve data from the temperature database was designed for pelagic research and does not allow for determining weighted vertical averages. Moreover, cod may experience different temperatures from what is measured at a fixed geographical point. Also there may be large variations in the temperature at one fixed point (e.g. in the proximity of the polar front) while the temperature at other points may be more stable during a year. The temperatures used in this study are therefore not to be confused with ambient temperatures for cod but must be regarded as indicators of spatial and temporal climatic variation.

\section{The spatial structure with respect to size-at-age}

The mean length predicted by Model (3) differ only slightly between areas (Fig. 3). This is to be expected since these results are based on all age groups of a highly migratory stock. Swimming performance increases with age, and older age groups (older than 4 years) utilize a progressively larger part of the Barents Sea. Any spatial structuring for these age groups should therefore be more limited: this can be seen from comparing age groups 5 and 6 years to age groups 2 to 4 years in Table I. By contrast, younger age 
groups (up to 4 years old) have a much more restricted migratory potential (Bergstad et al., 1987) and are thus more affected by local environmental conditions such as temperature. This expectation conforms well to the results presented in Table I and Fig. 3. An exception is the lack of a significant area effect for cod of age 1 years, which could be caused by problems with the sampling of very young individuals. The temperature dependence of length at age 1 years might also be influenced by the high and variable mortality experienced by $0+$ year fish, as they descend from the upper water layers in autumn (Ottersen et al., 1998).

The spatial structuring of cod with respect to size at age has not until the present investigation been studied in detail. Michalsen et al. (1998) showed that, south of $73^{\circ} \mathrm{N}$ and for the years 1988-1995, fish in the western part of the Barents Sea were in general larger than fish in the eastern part; this observation is corroborated by the present findings. Extending this previous research, the fine structure of length-at-age in the entire Barents Sea by dividing this study region into 11 areas has been analysed. How factors such as area, sex, year, age and temperature affect the growth of cod in the study region were tested by ANOVA, ANCOVA and linear regression. This revealed the north-south, east-west temperature gradient of the Barents Sea. Hence a considerable amount of the spatial variation in growth appears to be attributable to spatial variation in temperature.

Michalsen et al. (1998) showed that the distribution of cod is affected by year-class strength: strong year classes are more widely distributed than the poor ones. The constant observation grid for temperature used in this study does not account for this temporal variability in the temperatures experienced by cod in the northern and eastern areas. If it is important in the present analysis, it is expected that this potential bias leads to underestimating the climatic effect on growth.

\section{The dependence of length-at-age on temperature}

Temperature was included as a covariate in the ANOVA models to test to what degree area effects can be explained and removed by temperature. The results suggest that the spatial structure with respect to length-at-age is to a large degree caused by temperature differences. When included in Model (1), resulting in Model (3), this covariate increased the area effect on growth for all age groups (Table II). When temperature was included in Model (2), resulting in Model (4), it diminished the area effect (Table II). Significant area effects, however, remained even when temperature was included. This highlights both the limitations of simple temperature indices, and the presence of area effects not directly attributable to temperature.

Temporal variations in temperature within areas had a greater effect on growth than spatial variations in temperature within years (Fig. 2). This is not unexpected since the Barents Sea is an extreme environment for cod and seemingly small changes in temperature appear to greatly affect growth. Probably the effect of temperature is not 
Table II: ANCOVA results for (a) Model (3) (age 1 to 6) and (b) model (4) (all ages and ages 2-4)

\begin{tabular}{|c|c|c|c|c|c|}
\hline Age (years) & Source & d.f. & MS & $F$ & $P$ \\
\hline \multirow[t]{5}{*}{1} & Area & 10 & 28.77 & 6.90 & $<0.001$ \\
\hline & Year & 15 & 205.1 & 49.18 & $<0.001$ \\
\hline & Sex & 1 & 9.31 & 1.025 & 0.309 \\
\hline & Temperature & 1 & 8.79 & 2.11 & 0.147 \\
\hline & Residual & 3056 & 4.17 & & \\
\hline \multirow[t]{5}{*}{2} & Area & 10 & 213.8 & 13.69 & $<0.001$ \\
\hline & Year & 15 & 3052 & 195.5 & $<0.001$ \\
\hline & Sex & 1 & 30.25 & 3.156 & 0.023 \\
\hline & Temperature & 1 & 117.6 & 7.53 & 0.006 \\
\hline & Residual & 6223 & 15.62 & & \\
\hline \multirow[t]{5}{*}{3} & Area & $\overline{10}$ & 139.0 & 6.35 & $<0.001$ \\
\hline & Year & 15 & 6714 & 306.5 & $<0.001$ \\
\hline & Sex & 1 & 15.45 & 1.834 & 0.232 \\
\hline & Temperature & 1 & 139.3 & 6.36 & 0.012 \\
\hline & Residual & 7286 & 21.90 & & \\
\hline \multirow[t]{5}{*}{4} & Area & 10 & 227.7 & 8.95 & $<0.001$ \\
\hline & Year & 15 & 9455 & 371.6 & $<0.001$ \\
\hline & Sex & 1 & 96.02 & 6.21 & 0.009 \\
\hline & Temperature & 1 & 130.5 & 5.13 & 0.024 \\
\hline & Residual & 8157 & 25.45 & & \\
\hline \multirow[t]{5}{*}{5} & Area & 10 & 196.8 & 7.13 & $<0.001$ \\
\hline & Year & 15 & 8890 & 322.2 & $<0.001$ \\
\hline & Sex & 1 & 559.3 & 15.34 & $<0.001$ \\
\hline & Temperature & 1 & 56.90 & 2.06 & 0.151 \\
\hline & Residual & 6682 & 27.59 & & \\
\hline \multirow[t]{5}{*}{6} & Area & 10 & 225.7 & 7.02 & $<0.001$ \\
\hline & Year & 15 & 6069 & 188.8 & $<0.001$ \\
\hline & Sex & 1 & 20.96 & 2.147 & 0.148 \\
\hline & Temperature & 1 & 14.64 & 0.46 & 0.500 \\
\hline & Residual & 4524 & 32.15 & & \\
\hline \multirow[t]{6}{*}{ All ages } & Area & 10 & 1119 & 38.15 & $<0.001$ \\
\hline & Year & 15 & 25350 & 863.9 & $<0.001$ \\
\hline & Age & 8 & 928800 & 31650 & $<0.001$ \\
\hline & Sex & 1 & 2690 & 71.12 & $<0.001$ \\
\hline & Temperature & 1 & 0.499 & 0.02 & 0.896 \\
\hline & Residual & 38421 & 29.35 & & \\
\hline \multirow[t]{6}{*}{$2-4$} & Area & 10 & 511.8 & 20.72 & $<0.001$ \\
\hline & Year & 15 & 16370 & 662.8 & $<0.001$ \\
\hline & Age & 2 & 767900 & 31090 & $<0.001$ \\
\hline & Sex & 1 & 2168 & 60.97 & 0.012 \\
\hline & Temperature & 1 & 15.84 & 0.64 & 0.423 \\
\hline & Residual & 22017 & 24.70 & & \\
\hline
\end{tabular}


only direct, but also correlated with higher production in general, and with available capelin biomass in particular: inflowing warmer water masses are rich with zooplankton (Gjøsæter et al., 1992), thus increasing the distribution of capelin and its geographic overlap with cod. The longer response time to temperature fluctuations at age 3 and 4 years as compared to age 2 years (Fig. 2) indicates that the temperature has more pronounced effect on growth at early ages, and that the differences in length-at-age that arise in the early life may be preserved for several years. The positive effect of temperature on the length-at-age in the Barents Sea cod has earlier been demonstrated by Jørgensen (1992) and Michalsen et al. (1998). Despite the use of different aggregated temperature values, the influence of increasing temperature on length-at-age in the present study (Fig. 4) is of similar magnitude to that reported by Michalsen et al. (1998).

Because of the interaction between metabolic and ingestion rates, positive effects of increasing temperature on growth prevail only under a certain optimum temperature (Jobling, 1994). Given that the temperatures experienced by cod in the Barents Sea are well below this optimum (ca. $12-14{ }^{\circ} \mathrm{C}$; Jobling, 1988), it is not unexpected that increasing temperature has a positive effect on the growth. The temperature measure used in the present study, however, is only an index of ambient temperature. The actual temperatures experienced by fish depend on their movements along horizontal and vertical temperature gradients. Especially in the proximity of the polar front, ambient temperature of fish depends critically on their vertical distribution and movements. Recent studies utilizing data storage tags have shown that vertical movements of cod vary markedly in space and time and among individuals (Godø \& Michalsen, 2000; Stensholt, 2001). Because of this variability, temperature data from fixed positions should only be taken as indices of climatic conditions in the sea, thereby limiting the ability to explain growth variations with such temperature data.

Temperature preference of fish is only one of the several factors influencing its horizontal and vertical movements. Other important factors are availability of prey and avoidance of predators. Cod are known to track concentrations of pre-spawning capelin (Bogstad \& Mehl, 1997), and they may also migrate to cold water layers to forage, and return to warmer water to facilitate digestion (Stensholt, 2001). Small cod may also stay in deep, cold water in order to avoid predation by larger cannibalistic cod (Kristiansen et al., 2001).

\section{The effect of severity on predictability}

Cod growth in the Barents Sea is not only strongly affected by temperature (Harden Jones \& Scholes, 1974; Michalsen et al., 1998) but also by food access (Mehl \& Sunnanå, 1991; Bogstad \& Mehl, 1997). 'Disentangling' these effects is particularly difficult for cod in the Barents Sea because the most important prey species, capelin, are mainly distributed in very cold water (Gjøsæter, 1998). Consequently, growth could be slower at higher temperatures in the absence of capelin than at low temperatures with an excess of capelin. Since the polar front (Fig. 1) follows similar annual and seasonal movements as the ice edge (Loeng, 1989, 1991) and because capelin are usually 
distributed close to the polar front (Gjøsæter, 1998), a more complex dependence of growth on temperature is expected for the areas B3, C3 and D2.

The absence of similar confounding effects in area D1 may seem surprising as capelin is also distributed in this area. Due to the dominance of coastal water masses (Loeng, 1991) there is probably a lower degree of interaction between cod and capelin in this area than in the others. In addition, the effect found for areas B2, C1 and C2 could be caused by seasonal capelin migration through these areas (Gjøsæter, 1998). Unravelling the complex dependence of cod growth on the interplay between ambient temperature and food supply remains an interesting challenge for future investigations. 


\section{References}

Baranenkova, A. S. (1957). Comparative abundance of year classes of the cod and haddock in the Barents Sea according to the quantitative estimation of the young fish and the data on fisheries. Trudy PINRO 10, 54-77.

Bergstad, O. A., Jørgensen, T. \& Dragesund, O. (1987). Life history and ecology of the gadoid resources of the Barents Sea. Fisheries Research 5, 119-161.

Bogstad, B. \& Mehl, S. (1997). Interactions between Atlantic cod (Gadus morhua) and its prey species in the Barents Sea. Alaska Sea Grant College Program AK-SG97-01, 591-615

Brander, K. (1995). The effect of temperature on growth of Atlantic cod (Gadus morhua L.). ICES Journal of Marine Science 52, 1-10.

Clarke, A. (1993). Seasonal acclimatization and latitudinal compensation in metabolism: do they exist? Functional Ecology 7, 139-149.

Gjøsæter, H. (1998). The population biology and exploitation of capelin (Mallotus villosus) in the Barents Sea. Sarsia 83, 453-496.

Gjøsæter, H., Godø, O. R. \& Ulltang, Ø. (1992). De viktigste fiskeslagene i Barentshavet. In Økosystem Barentshavet (Sakshaug E., Bjørge, A., Gulliksen, B., Loeng, H. \& Mehlum, F., eds.), pp. 181-202. Oslo: Universitetsforlaget (in Norwegian)

Godø, O. R. \& Michalsen, K. (2000). Migratory behaviour of north-east Arctic cod, studied by use of data storage tags. Fisheries Research 48, 127-140.

Godø, O. R. \& Sunnanå, K. (1992). Size selection during trawl sampling of cod and haddock and its effect on abundance indices at age. Fisheries Research 13, 293310.

Harden Jones, F. R. \& Scholes, P. (1974). The effect of low temperature on cod, Gadus morhua. Journal du Conseil International pour l'Exploration de la Mer 35, 258271.

Jobling, M. (1988). A review of the physiological and nutritional energetics of cod, Gadus morhua L., with particular reference to growth under farmed conditions. Aquaculture 70, 1-19.

Jobling, M. (1994). Fish Bioenergetics. London: Chapman \& Hall.

Jørgensen, T. (1992). Long term changes in growth of Northeast Arctic cod (Gadus morhua) and some environmental influences. ICES Journal of Marine Science 49, 263-277.

Kristiansen, T. S., Michalsen, K., Jacobsen, J. A. \& Huse, I. (2001). Optimal selection of temperature areas by juvenile cod (Gadus morhua L.) in the Barents Sea modelled by dynamic optimisation. ICES Journal of Marine Science 58, 172-182. doi: $10.1006 / j m s c .2001 .1000$ 
Loeng, H. (1989). The influence of temperature on some fish population parameters in the Barents Sea. Journal of Northwest Atlantic Fishery Science 9, 103-113.

Loeng, H. (1991). Features of the physical oceanographic conditions in the Barents Sea. Polar Research 10, 5-18.

Maslov, N. A. (1944). The bottom fishes of the Barents Sea and their fisheries. Trudy PINRO 8, 3-186.

Maslov, N. A. (1960). Soviet investigations on the biology of cod and other demersal fish in the Barents Sea. In Sovetskie rybochozjajstvennye issledovanija v morjach Evropejskogo Severa (Soviet Fisheries Investigations in North European Seas) (Ju. Ju. Marti, ed.), pp. 185-231. Moscow: VNIRO.

Mehl, S. \& Sunnanå, K.1991. Changes in growth of Northeast Arctic cod in relation to food consumption in 1984-1988. ICES Marine Science Symposia 193, 109-112.

Michalsen, K., Ottersen, G. \& Nakken, O. (1998). Growth of North-east Arctic cod (Gadus morhua L.) in relation to ambient temperature. ICES Journal of Marine Science 55, 863-877. doi: 10.1006/jmsc.1998.0364

Nakken, O. \& Raknes, A. (1987). The distribution and growth of Northeast Arctic cod in relation to bottom temperatures in the Barents Sea, 1978-1984. Fisheries Research 5, 243-252.

Ottersen, G., Michalsen, K. \& Nakken, O. (1998). Ambient temperature and distribution of north-east Arctic cod. ICES Journal of Marine Science 55, 67-85. doi: 10.1006/jmsc.1997.0232

Shevelev, M. S., Tereschenko, V. V. \& Yaragina, N. A. (1987). Distribution and behavior of demersal fishes in the Barents and Norwegian Seas, and the factors influencing them. In The Effect of Oceanographic Conditions on Distribution and Population Dynamics of Commercial Fish Stocks in the Barents Sea. Proceedings of the Third Soviet-Norwegian symposium, Murmansk (Loeng, H., ed.), pp. 181190. Bergen: Institute of Marine Research.

Stensholt, B. K. (2001) Cod migration patterns in relation to temperature: analysis of storage tag data. ICES Journal of Marine Science 58, 770-793. doi: 10:1006/jmsc.2001.1607

\section{Electronic Reference}

ICES (International Council for the Exploration of the Sea) (2001). Report of the Northern Pelagic and Blue Whiting Fisheries Working Group. ICES CM 2001/ACFM:17. http://www.ices.dk/reports/acfm/2001/wgnpbw/wgnpbw01.pdf. 